\title{
APPLICATION OF COMBINED SORBENT FOR PROCESS OF WATER PURIFICATION FROM MICROBIAL CONTAMINATION
}

\author{
Irina Martemianova ${ }^{1, *}$, Sergey Zhuravkov ${ }^{1}$, Evgenii Plotnikov ${ }^{1}$, Dmitrii Martemianov ${ }^{1}$, \\ Elena Korotkova ${ }^{1}$, Bohumil Kratochvil ${ }^{1}$, Olesya Voronova $^{1}$ and Svetlana Antonova ${ }^{1}$ \\ ${ }^{1}$ Tomsk Polytechnic University, Lenin av. 30, Tomsk, 634050, Russia
}

\begin{abstract}
The results of sorption efficiency of filter material which was obtained on the base of river sand and modified by aluminium oxyhydroxide with the sol-gel process are presented. All components were tested as sorbents, and their properties were compared. New filter material was found effective in the process of water treatment from bacterial contamination.
\end{abstract}

\section{Introduction}

Microbiological contaminant is a special challenge among the various pollutants that are in the hydrosphere. Different microorganisms can cause a lot of negative consequences both in industrial and home use, and it take a lot of effort to treat consequences of that including health loss, necessity of antibacterial drugs development, etc [1-4]. Obviously, it is an important task to eliminate bacteria from water. Various water treatment methods, including chemical treatment (chlorination, ozonation), membrane cleaning, UV sterilization, modified filter materials are used to prevent the negative effects associated with the use of contaminated water [5]. In recent years, a lot of attention is paid to development and spread of modified sorptive filter materials in combination with silver and aluminum nanoparticles, which have several advantages over other methods of treatment [6-10]. Therefore, the creation of new modified materials with improved sorption, filtration properties, and low cost, has relevance.

The aim of this work is to study some physical and chemical properties of the samples of the combined filter material and its components (in the form of aluminum oxyhydroxide and sand), as well as to determine the extraction degree of the bacteria Escherichia Coli (E.coli) from the model contaminated solution by the test samples of the modified materials.

\section{Materials and methods}

* Corresponding author: martemiv@yandex.ru 
The objects of the present study were the sand from the Ob river (Kireevsk, Tomsk region) with the particle size of $0.1-0.7 \mathrm{~mm}$, aluminum oxyhydroxide $(\mathrm{AlO}(\mathrm{OH}))$ synthesized from aluminum food grade AK7 (the particle size is less than $0.1 \mathrm{~mm}$ ) and the modified filter material from the specially treated river sand and aluminum oxyhydroxide.

Surface morphology of all the samples of aluminum oxyhydroxide and river sand was studied with the transmission electron microscopy (the transmission electron microscope JEM-2100F (JEOL, Japan) with the system of sample preparation EM-09100IS "Ion Slicer".

The specific surface area $\left(\mathrm{S}_{\mathrm{sp}}\right)$ and pore volume $\left(\mathrm{P}_{\mathrm{sp}}\right)$ in all the studied samples were determined using the analyzer "SORBTOMETR $\mathrm{M}$ " with the method of thermal desorption of nitrogen (BET).

The bacteria Escherichia Coli (strain Escherichia coli ATCC25922) were used as the contaminating microbial agent for the experiment. The bacteria E.coli were filtered under dynamic conditions using the peristaltic pump for water suspension. A suspension of bacteria passed through a tube filled with the test sample of the material. The following samples were prepared for the filtration test: the river sand, aluminum oxyhydroxide, and three samples of the combined sorbent with different contents of the active ingredient, were obtained by mixing. All the test materials were placed in the glass tubes (length - $150 \mathrm{~mm}$, internal diameter $-8 \mathrm{~mm}$ ) to determine the filtration capacity. The weight and composition of the materials in the tubes were: sand - $10.3 \mathrm{~g}$; aluminum oxyhydroxide - $7 \mathrm{~g}$; sorbent \# 1 (sand 90\%/10\% aluminum oxo-hydroxide - $9.94 \mathrm{~g}$ ); sorbent \# 2 (sand 80\%/20\% aluminum oxo-hydroxide - $9.64 \mathrm{~g}$ ); sorbent \# 3 (sand 70\%/30\% aluminum oxo-hydroxide - $9.3 \mathrm{~g}$ ). The test bacterial suspension was prepared in tap water, it was settling for 1 day. Then, the water was added to the 24-hour culture of Escherichia Coli in the meat-peptone broth. The final concentration of the bacterial suspension was $2.3 \times 10^{7} \mathrm{CFU} / \mathrm{cm}^{3}$. The total number of microorganisms (TMC) in the sample bacterial suspension was determined according to the Methodological Instructive Regulations MUK 4.2.1018-01. After filtering, the samples of the suspension were placed in the petri dishes. The results were analyzed in 24 hours by counting the number of colonies expressed in the colony forming units (CFU) per $1 \mathrm{~cm}^{3}$ of the sample.

\section{Results}

Figure 1 shows the agglomeration of the aluminum oxyhydroxide nanoparticles $(19000 \times)$. The size of the separate nanoparticle is about 50-200 nm in length and $2 \mathrm{~nm}$ in diameter. Figure 2 shows the particle of the river sand with a magnification of 5000 times.

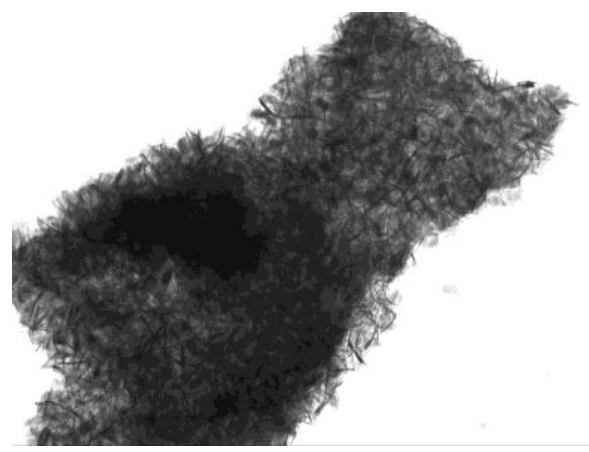

Fig. 1. Agglomeration of the aluminum oxyhydroxide nanoparticles (19000×). 


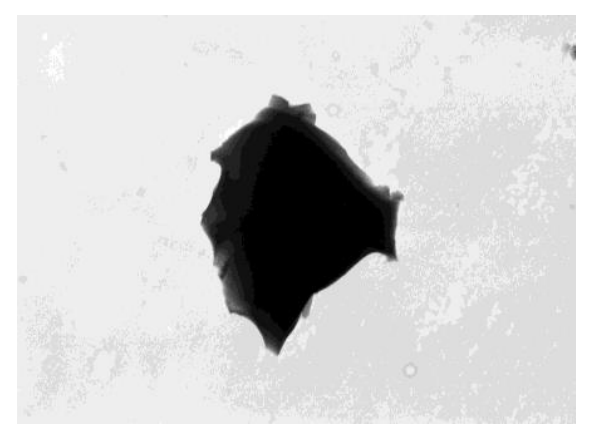

Fig. 2. River sand particle with the transmission electron microscopy (5000×).

As shown, the sand particle surface is very smooth opposite to the aluminum nanoparticles with the clearly visible needles on the surface. According to this image, the low specific surface value and possible absent or very low porosity of the sand material and, consequently, low adsorbent properties were predicted. It was completely proved by the method of thermal desorption of nitrogen (Table 1). Presumably, sand could be used as very cheap and available mineral base for modified adsorbent production. Table 1 summarizes the specific surface area and pore volume of all the tested material samples.

Table 1. The specific surface area and pore volume of the initial and combined materials

\begin{tabular}{|c|c|c|}
\hline Sample & $\mathbf{S}_{\mathrm{sp}}, \mathbf{m}^{\mathbf{2}} / \mathbf{g}$ & $\mathbf{P}, \mathbf{c m}^{\mathbf{3}} / \mathbf{g}$ \\
\hline River sand & 0.444 & 0 \\
\hline $\begin{array}{c}\text { Aluminum } \\
\text { oxyhydroxide }\end{array}$ & 192.5 & 0.083 \\
\hline Sorbent \# 1 & 20.37 & 0.009 \\
\hline Sorbent \# 2 & 40.41 & 0.017 \\
\hline Sorbent \# 3 & 62.8 & 0.025 \\
\hline
\end{tabular}

The results revealed the smallest value of the specific surface and absence of pores in the river sand samples. Aluminum oxyhydroxide has the highest values of all the studied parameters. The values of the specific surface and porosity of the modified sorbents increase with a rise in the active component of the sample.

Figure 3 shows the sorption properties of the material samples for extraction of the Escherichia Coli culture from the model solution under dynamic conditions. 


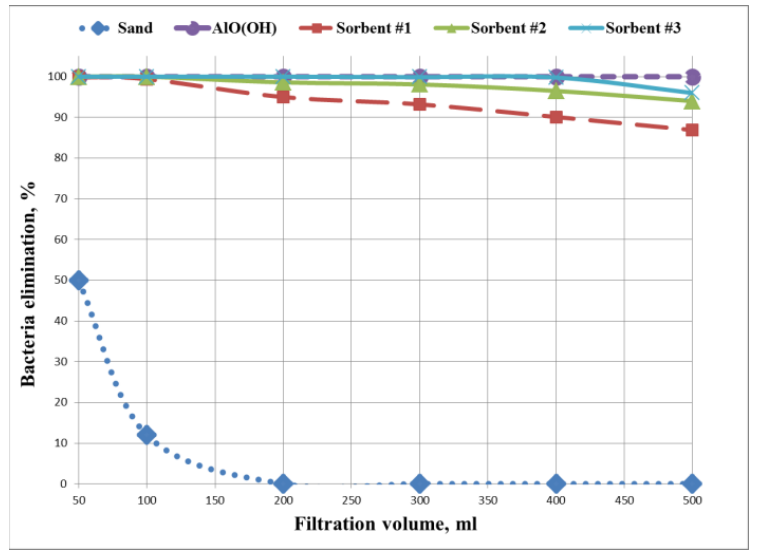

Figure 3. The degree of bacteria elimination vs. different filtration volumes.

The data showed (Figure 3) that the river sand does not remove notable number of microorganisms from the aqueous suspension but has a low flow resistance, therefore, the process has high performance $\left(250 \mathrm{~cm}^{3} / \mathrm{h}\right)$. The lowest effectiveness revealed in this test makes the non-modified sand inappropriate for microbiological filtration.

Opposite to the sand, aluminum oxyhydroxide completely removed bacteria Escherichia Coli via the filtration process. However, a very high flow resistance of the material was determined, so the filtration performance was $5 \mathrm{~cm}^{3} / \mathrm{h}$.

Among the combined sorbents, the best filtering properties showed the sorbent \#3, the worst one was the sorbent \#1. Filtration performance of the sorbents was as follows: the sorbent \#1 $-223 \mathrm{~cm}^{3} / \mathrm{h}$; the sorbent \#2-197 $\mathrm{cm}^{3} / \mathrm{h}$; the sorbent $\# 3-152 \mathrm{~cm}^{3} / \mathrm{h}$. So, the flow resistance of the material decreased with fall in aluminum in the sorbent.

\section{Conclusion}

The surface morphology of the river sand and aluminum oxyhydroxide nanofibers was investigated, the sizes of aluminum oxyhydroxide nanofibers were determined - length of 50-200 nm; width of $2 \mathrm{~nm}$. It was found that the bicomponent composite sorbents exhibit good extraction rate of the bacteria Escherichia Coli from the test suspension at a high flow rate. Increased quantities of the active component in the samples of the combined sorbent lead to the improved filtration properties of the material. The river sand was shown as an ineffective agent for microbiological water treatment. In turn, the aluminum oxyhydroxide completely removes the bacteria from the contaminated water but has very low hydrodynamic properties.

Thus, a prospective way of production and effective use of the combined sorbent based on the river sand mixed with aluminum oxyhydroxide to extract the microbiological contaminants from aqueous media was shown.

This work was supported by the grant of the President of the Russian Federation for young Russian scientists MK-5939.2016.8

\section{References}

1. Y. Chen et al, Acta Scientiae Circumstantiae 35, 337-351, (2015) 
2. M. Telitchenko, S. Ostroumov, Introduction to Problems of Biochemical Ecology: Biotechnology, agriculture, protection of the environment. (Moscow: Science, 1990)

3. E. Plotnikov, V. Pehenko, V. Plotnikov, Physiology and Pharmacology 19, 247-252, (2015) https://www.scopus.com/record/display.uri?eid=2-s2.0$\underline{\text { 84960958582\&origin }=\text { inward\&txGid=2A01D10CFF2B47942E9AAD44C40053BD.ws }}$ nAw8kcdt7IPYLO0V48gA\%3a1

4. E. Plotnikov, V. Silnikov, A. Gapeyev, V. Plotnikov, Advanced Pharmaceutical Bulletin 6, 71-74, (2016) http://dx.doi.org/10.15171/apb.2016.011

5. V. Kosoy, A. Bazhenov, Water and Ecology: Problems and Solutions (Rus). 1, 40-45, (2001)

6. S. Zhuravkov, E. Plotnikov, D. Martemiyanov, N. Yavorovsky, U. Hasse, S. Zander, Advanced material research 872, 74-78, (2014) http://dx.doi.org/10.4028/www.scientific.net/AMR.872.74

7. D. Martemianov, E. Korotkova, A. Galanov, Bulletin of the Karaganda University 3, 61-65, (2012)

8. E. Plotnikov, I. Martemianova, D. Martemianov, S. Zhuravkov, O. Voronova, E. Korotkova, V. Silnikov, Procedia Chemistry 15, 219-224, (2015) http://www.sciencedirect.com/science/article/pii/S187661961500114X

9. E. Plotnikov, S. Zhuravkov, A. Gapeyev, V. Plotnikov, D. Martemiyanov, Advanced material research 1040 , $65-70$,

(2015) http://dx.doi.org/10.4028/www.scientific.net/AMR.1040.65

10. E. Plotnikov, I. Martemianova, D. Martemianov, S. Zhuravkov, T. Kan, O. Voronova, Journal of Materials and Environmental Science 7 (11), 3944-3948, (2016) http://www.jmaterenvironsci.com/Document/vol7/vol7 N11/423-JMES-2509$\underline{\text { Plotnikov.pdf }}$ 